\title{
Factors Controlling the Formation of Akinetes Adjacent to Heterocysts in the Cyanobacterium Cylindrospermum licheniforme Kütz.
}

\author{
By TAKAYASU HIROSAWA* AND C. PETER WOLK $\uparrow$ \\ $M S U$-DOE Plant Research Laboratory, Michigan State University, \\ East Lansing, Michigan 48824, U.S.A.
}

(Received 18 November 1978)

\begin{abstract}
Substances which stimulate the formation of akinetes (spores) in Cylindrospermum licheniforme Kütz. are secreted into a phosphate-free sporulation medium by filaments of that cyanobacterium. One such substance, purified from the centrifugal supernatant fluid of sporulating cultures, initiated sporulation in a phosphate-containing culture medium. Certain amino acids, particularly tryptophan, and calcium glucuronate also strongly stimulated sporulation. Acetylene and ethylene were inhibitory. No significant effect of cyclic nucleotides was observed.

The addition of 12.5 to $15 \%(\mathrm{v} / \mathrm{v}) \mathrm{H}_{2}$ stimulated sporulation in air or under $\mathrm{CO}_{2} / \mathrm{O}_{2} / \mathrm{Ar}$ $(0 \cdot 1: 19 \cdot 9: 80$, by vol.) by up to $2 \cdot 5$-fold, but did not significantly affect the reduction of acetylene by intact filaments. Thus, the stimulation of sporulation by hydrogen was not mediated by an effect on the fixation of nitrogen. Hydrogen uptake in a cell-free suspension derived from whole filaments was detected manometrically, with phenazine methosulphate as electron acceptor, at a rate of $5.8 \mu \mathrm{mol} \mathrm{H}_{2}(\mathrm{mg} \text { chlorophyll } a)^{-1} \mathrm{~h}^{-1}$. The uptake hydrogenase activity derived from isolated heterocysts accounted for $84 \pm 2 \%$ of the uptake hydrogenase activity from whole filaments, whereas no activity was detected in a fraction derived from the vegetative cells.

The formation of the pattern consisting of spores contiguous with heterocysts may be controlled by either, or a combination of, (i) a sporulation-stimulatory substance, if that substance is synthesized solely in heterocysts, or (ii) some substance the concentration of which may be controlled by hydrogen assimilated by heterocysts.
\end{abstract}

\section{INTRODUCTION}

In certain filamentous cyanobacteria (blue-green algae) there are three distinct types of cells arrayed in one-dimensional patterns; two, the heterocyst and the akinete (spore), arise by differentiation of the third type, the vegetative cell. In Cylindrospermum licheniforme Kütz., the heterocysts are normally present only at terminal positions in the filaments, and the akinetes form subterminally, adjacent to the heterocysts. Mature akinetes of $C$. licheniforme are cylindrical cells surrounded by a thick envelope. Their diameter (about $20 \mu \mathrm{m}$ ) is twice, and their length (about $40 \mu \mathrm{m}$ ) is three to four times, as great as the corresponding dimensions of vegetative cells. Like vegetative cells, they contain photosynthetic thylakoids, glycogen (Zastrow, 1953) and also cyanophycin granules, which consist of copolymers of aspartic acid and arginine (Simon, 1971). In some cyanobacteria, the formation of akinetes is promoted by the absence of phosphate from the medium (Wolk, 1965; Gentile \&

\footnotetext{
* Present address: 2-5-13 Ikeda, Kawasaki, Kanagawa, Japan.
}

$\dagger$ To whom requests for reprints should be sent. 
Maloney, 1969; see also Glade, 1914) or by high concentrations of other nutrients (Tyagi, 1974; Canabaeus, 1929).

Cyanobacteria secrete growth-inhibitory and toxic substances (Harder, 1917; Prescott, 1960; Hartman, 1960; Jakob, 1961; Jackim \& Gentile, 1968); and growth-stimulatory materials (Fogg, 1952; Walsby, 1974), including a substance which chelates iron with high affinity (Simpson \& Neilands, 1976). The non-dialysable extracellular products of Anabaena cylindrica decrease the toxic effect of polymixin B against Anabaena cylindrica and Anacystis nidulans, but show no effect on the formation of akinetes by Anabaena species (Whitton, $1965,1967)$. Fisher \& Wolk (1976) reported that the culture filtrate from an akinete-forming culture of Cylindrospermum licheniforme in phosphate-free standard sporulation medium (SSM) stimulated the formation of akinetes in a fresh inoculum, without affecting its growth. Supplementation of the culture filtrate with all of the constituents of SSM did not affect the stimulation by the filtrate. They therefore concluded that the stimulation of sporulation by the culture filtrate was due not to depletion of the medium but to a substance or substances released into the medium.

The participation of heterocysts in the formation of akinetes has long been suggested for those instances in which there is a close spatial relationship between the two types of cells. Wolk (1966) provided the first experimental evidence in support of the idea that heterocysts play a role in the sporulation of contiguous vegetative cells. Having separated heterocysts from neighbouring vegetative cells by gentle agitation, he observed that the vegetative cells detached from heterocysts, although appearing undamaged, failed to differentiate into akinetes.

Heterocysts are the sole sites of nitrogen fixation in aerobically grown, heterocyst-forming cyanobacteria (Stanier \& Cohen-Bazire, 1977; Haselkorn, 1978; Peterson \& Wolk, 1978 b). However, the heterocysts depend on vegetative cells for the electron donors and carbon skeletons necessary for nitrogen fixation (Wolk, 1968; Winkenbach \& Wolk, 1973; Thomas et al., 1977). Hydrogen, assimilated by an uptake hydrogenase which is restricted to heterocysts, at least in Anabaena 7120 (Peterson \& Wolk, 1978a), can also serve as electron donor to nitrogenase in heterocysts (Peterson \& Wolk, 1978b). Furthermore, heterocysts reduce 2,3,5-triphenyltetrazolium chloride more rapidly than do vegetative cells (Drews, 1955; Drawert \& Tischer, 1956; Talpasayi \& Bahal, 1967; Stewart et al., 1969; Fay \& Kulasooriya, 1972). Reducing power necessary for nitrogen fixation in heterocysts can be produced by oxidative metabolism of carbohydrate (Apte et al., 1978; Lockau et al., 1978; see also Winkenbach \& Wolk, 1973; Lex \& Carr, 1974).

Results reported in the present communication relate sporulation adjacent to heterocysts to common metabolites, to a specific sporulation-stimulatory substance and to the metabolism of hydrogen.

\section{METHODS}

Culture conditions. Stock cultures of Cylindrospermum licheniforme Kütz. ATCC 29412 were grown axenically in $50 \mathrm{ml}$ of an eightfold dilution (AA/8) of Allen and Arnon's (1955) medium in $125 \mathrm{ml}$ Erlenmeyer flasks. The cultures were grown on a reciprocating shaker $\left(107 \mathrm{rev} . \mathrm{min}^{-1}\right)$ in continuous light $\left(20 \mathrm{~W} \mathrm{~m}^{-2}\right)$ from cool-white fluorescent lamps, at $26 \pm 1{ }^{\circ} \mathrm{C}$, and were subcultured $(1 \%, \mathrm{v} / \mathrm{v})$ weekly in order to prevent the formation of akinetes. Phosphate-free standard sporulation medium (SSM) was prepared as described previously (Wolk, 1965) except that $N$-tris(hydroxymethyl)methyl-2-aminoethanesulphonic acid (TES) was used as buffer in place of DL-alanylglycine, and the pH was adjusted to $7 \cdot 5$. For studies of hydrogenase, stock cultures were inoculated into 201 glass carboys containing $161 \mathrm{AA} / 8$, and were aerated with compressed air and exposed to continuous light $\left(88 \mathrm{~W} \mathrm{~m}^{-2}\right)$ from cool-white fluorescent lamps, at $25 \pm 2{ }^{\circ} \mathrm{C}$.

Bioassay of substances influencing the formation of akinetes. Bioassays were performed under the same conditions of light, temperature and agitation as described for the growth of stock cultures. An assay mixture consisted of $4 \mathrm{ml}$ of the material being tested, dissolved in SSM, plus $1 \mathrm{ml}$ of a suspension of filaments of C. licheniforme in SSM, in a $50 \mathrm{ml}$ Erlenmeyer flask. The $\mathrm{pH}$ of the test solution was adjusted to $7 \cdot 5$, and the 
solution was sterilized by filtration through a $0.22 \mu \mathrm{m}$ pore-size membrane filter. The cells to be resuspended in SSM for bioassay were collected from 1 week-old stock cultures by centrifugation. Chlorophyll $a$ content was determined by measurement of the absorbance at $665 \mathrm{~nm}$ of methanolic extracts of $C$. licheniforme (Mackinney, 1941). The initial concentration of chlorophyll $a$ in an assay mixture containing cyanobacteria was $0 \cdot 11 \mu \mathrm{g} \mathrm{ml}^{-1}$. After $3 \frac{1}{2}$ to $4 \mathrm{~d}$, the number of akinetes attached to a sample of 200 heterocysts was counted. A cell was considered to be a heterocyst if it was present at a terminal position on a filament, had a thick envelope and contained a polar granule (Clark \& Jensen, 1969). Cells were considered to be akinetes only if they were at least twice as long as a normal vegetative cell and were wider than heterocysts (Simon, 1977).

For bioassays under different gas phases, $20 \mathrm{ml}$ of cell suspension in SSM $\left(0 \cdot 11 \mu \mathrm{g}\right.$ chlorophyll $\left.a \mathrm{ml}^{-1}\right)$ were placed in $250 \mathrm{ml}$ filter flasks (effective volume, $280 \mathrm{ml}$ ) modified as follows. The side-arm of a flask was sealed with a rubber serum stopper. The mouth of the flask was fitted with a rubber stopper penetrated by glass tubing $(1.5 \mathrm{~mm}$ i.d.) which reached to the bottom of the flask. The glass tubing was connected via silicon rubber tubing to a $0.22 \mu \mathrm{m}$ pore-size membrane filter. The flask, vented through a hypodermic needle inserted through the serum stopper, was flushed with gas or a mixture of gases via the membrane filter and tubing, and then the needle was removed and the tubing was clamped shut. Measured portions of other gases, sterilized by membrane filtration, were then injected, and excess pressure was released through the side-arm with a gas-tight syringe. The mixtures of gases were replaced every $12 \mathrm{~h}$.

Assay for hydrogenase. Hydrogen uptake was measured manometrically at $30^{\circ} \mathrm{C}$ using a Gilson differential respirometer (Gilson Medical Electronics, Middleton, Wis., U.S.A.). Test sample ( $1.8 \mathrm{ml}), 100 \mathrm{~mm}$ electron acceptor $(0.2 \mathrm{ml})$ and $5 \mathrm{M}-\mathrm{KOH}(0.1 \mathrm{ml})$ were placed, respectively, in the side-arm, main chamber and centre well of a Warburg flask filled with hydrogen. The reaction was initiated by adding the test sample to the solution of electron acceptor.

Isolation of heterocysts. Heterocysts were isolated by the method of Peterson \& Wolk (1978b). Cells were harvested by centrifugation at $17300 \mathrm{~g}$ (RC-2B centrifuge equipped with an SS-34 rotor and a continuous flow attachment; Dupont-Sorvall, Norwalk, Conn., U.S.A.) and were resuspended in approximately $30 \mathrm{ml}$ medium. The suspension was placed in a centrifuge tube fitted with a serum stopper, and the tube was twice evacuated to $0.05 \mathrm{mmHg}(7 \mathrm{~Pa})$ and refilled to $1 \mathrm{~atm}$ with $\mathrm{H}_{2}$. All subsequent operations were performed under $\mathrm{H}_{2}$, except that the buffers were thoroughly sparged with $\mathrm{N}_{2}$ and the effluents from the Ribi press (see below) were briefly held under $\mathrm{N}_{2}$. Cells were centrifuged $(500 \mathrm{~g}, 10 \mathrm{~min})$, resuspended in buffer $(\mathrm{pH} 7 \cdot 2)$ containing $10 \mathrm{~mm}-N$-2-hydroxyethylpiperazine- $N^{\prime}$-2-ethanesulphonic acid (HEPES), $10 \mathrm{~mm}$-piperazine- $N, N^{\prime}$ bis-2-ethanesulphonic acid (PIPES), $1 \mathrm{mM}-\mathrm{MgCl}_{2}$ and $1 \mathrm{~mm}$-cysteine (HP buffer), centrifuged again as before, and then resuspended in $40 \mathrm{ml}$ of similar buffer to which had been added $10 \mathrm{mM}-\mathrm{Na}_{2}$ EDTA and $1.0 \mathrm{mg}$ lysozyme $\mathrm{ml}^{-1}$. The suspension was shaken at $200 \mathrm{rev}$. $\mathrm{min}^{-1}$ in a reciprocating shaker water bath at $30^{\circ} \mathrm{C}$ for $30 \mathrm{~min}$, and was then centrifuged $(500 \mathrm{~g}, 5 \mathrm{~min})$. The pellet was resuspended in $30 \mathrm{ml} \mathrm{HP}$ buffer. The suspension was transferred to a stoppered $125 \mathrm{ml}$ Erlenmeyer flask and was cavitated in a sonic cleaning bath at 12 to $13{ }^{\circ} \mathrm{C}$ for 20 to $30 \mathrm{~min}$ until the ratio of vegetative cells to heterocysts decreased to 0.02 . Heterocysts were sedimented $(500 \mathrm{~g}, 5 \mathrm{~min})$, and the supernatant fluid was collected as a vegetative cell fraction. The heterocyst-containing pellet was washed twice with HP buffer. The isolated heterocysts and intact filaments were resuspended in HP buffer and were totally disrupted with a Ribi press (Dupont-Sorvall) at a pressure of $140 \mathrm{MPa}$.

Chemicals. Phenazine methosulphate was obtained from Calbiochem, calcium glucuronate from Mann Research Laboratories (New York, N.Y., U.S.A.) and all gases from Matheson Gas Products (East Rutherford, N.J., U.S.A.). All other chemicals were obtained from Sigma.

\section{RESULTS}

Time course of production of factors stimulating the formation of akinetes. Cylindrospermum licheniforme, inoculated from a stock culture into SSM, grew actively for $12 \mathrm{~d}$ (Fig. 1). Akinetes were produced in the period from 4 to $12 \mathrm{~d}$. After $12 \mathrm{~d}$, more than $80 \%$ of the heterocysts were accompanied by akinetes. After $14 \mathrm{~d}$, the filaments fragmented and the heterocysts became detached from the filaments. Samples of supernatant fluid taken every other day were lyophilized and extracted with methanol, and the methanolic extracts were dried, redissolved in SSM and bioassayed. Figure 2 shows the percentage of heterocysts with contiguous akinetes after $4 \mathrm{~d}$ of bioassay. A stimulation of the formation of akinetes was first demonstrable using the methanolic extract of the supernatant from the $2 \mathrm{~d}$-old culture, and then increased monotonically for $10 \mathrm{~d}$. 


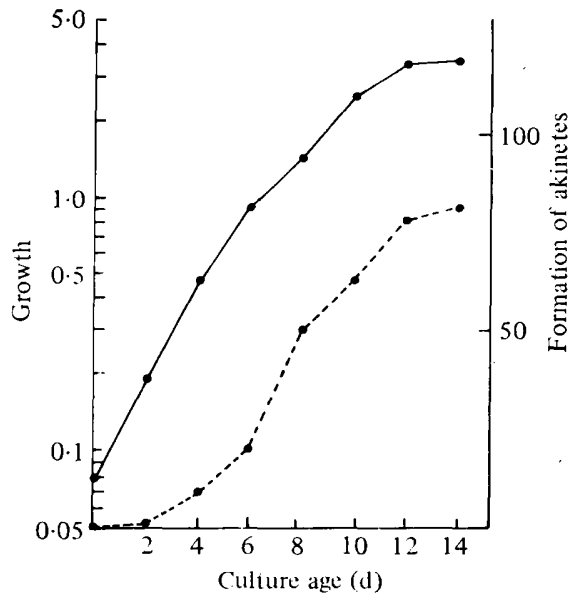

Fig. 1

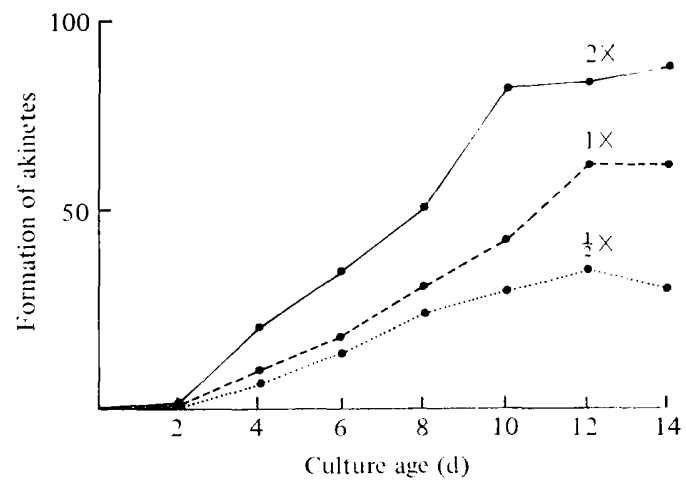

Fig. 2

Fig. 1. Growth of Cylindrospermum licheniforme and formation of akinetes in SSM. Growth (- - ) is expressed as $\mu \mathrm{g}$ chlorophyll $a \mathrm{ml}^{-1}$. The formation of akinetes (---) is expressed as the percentage of heterocysts with a contiguous akinete. Samples $(100 \mathrm{ml})$ were taken from a 11 culture every $2 \mathrm{~d}$.

Fig. 2. Production of material stimulating the formation of akinetes, as measured by bioassay of its stimulatory activity. Centrifugal supernatants from the culture of Fig. 1 were lyophilized and extracted with methanol, and the methanolic extracts were dried and redissolved in SSM. The activities are expressed as the percentage of heterocysts with contiguous akinetes after $4 \mathrm{~d}$ incubation. The concentration of solids in the suspensions used for bioassay of the culture filtrate, relative to their concentration in the original filtrate, are indicated: $2 \times, 1 \times, \frac{1}{2} \times$. The control value $(3.5 \%$ heterocysts with a contiguous akinete) obtained with $0 \times$ filtrate, i.e. SSM, has been subtracted from the data as presented.

Isolation, from cells, of material stimulating the formation of akinetes. Cells from the same 1001 of sporulating cultures used for an experiment in the following paper (i.e. Table 1 in Hirosawa \& Wolk, 1979) were collected by centrifugation, washed with fresh SSM and lyophilized. The lyophilized cells $(15.45 \mathrm{~g}$ dry wt) were extracted three times with $250 \mathrm{ml}$ absolute methanol. The combined extracts were evaporated to dryness and resuspended in $20 \mathrm{ml}$ distilled water. Low concentrations of the extract showed significant sporulationstimulatory activity (Table 1 ).

Effect of hydrogen on the formation of akinetes. When a suspension of filaments in SSM was gassed with $12.5 \%$ hydrogen $/ 87.5 \%$ air, the formation of akinetes in SSM was stimulated 2.5-fold relative to a control gassed with air (Table 2). Growth was not affected. Hydrogen was also stimulatory when added to a gas mixture of $0 \cdot 1 \% \mathrm{CO}_{2} / 19 \cdot 9 \% \mathrm{O}_{2} / 80 \%$ Ar (Table 2). Under a gas phase of air $/ 10 \%$ acetylene $/ 0$ to $15 \% \mathrm{H}_{2}$, C. licheniforme showed no significant variation in its rate of formation of ethylene $[12.1 \pm 1.0 \mu \mathrm{mol}(\mathrm{mg}$ chlorophyll $a)^{-1} \mathrm{~h}^{-1}$.

Uptake hydrogenase and its localization. Ferricyanide $\left(E_{0}^{\prime}+429 \mathrm{mV}\right)$, which served as electron acceptor in a cell-free preparation of Anabaena 7120 (Peterson \& Wolk, 1978a), could not do so in a cell-free preparation of $C$. licheniforme. 2,6-Dichlorophenolindophenol, methylene blue and methyl viologen $\left(E_{0}^{\prime}+217,+11\right.$ and $-550 \mathrm{mV}$, respectively) were also not measurably active as electron acceptors. At $10 \mathrm{mM}$, phenazine methosulphate $\left(E_{0}^{\prime}+80 \mathrm{mV}\right)$ was active as an acceptor, at a rate of $5 \cdot 8 \mu \mathrm{mol} \mathrm{H}_{2}$ (mg chlorophyll $\left.a\right)^{-1} \mathrm{~h}^{-1}$. Phenazine methosulphate was the most effective electron acceptor which had been tried with the uptake hydrogenase from $A$. cylindrica (Fujita et al., 1964). On a per heterocyst basis and as measured by in-vitro assays, $84 \pm 2 \%$ (two experiments) of the hydrogenase activity in whole filaments $\left[3.03 \mu 1 \mathrm{H}_{2}\right.$ taken up $\left.\left(10^{9} \text { heterocysts }\right)^{-1} \mathrm{~min}^{-1}\right]$ was recovered in 
Table 1. Sporulation-stimulatory activity of an extract of cells

Lyophilized cells $(0.154 \mathrm{mg}$ dry wt per $\mathrm{ml}$ original suspension) were extracted with absolute methanol, and the methanolic extract was dried, redissolved and bioassayed.

$\begin{array}{cc}\begin{array}{c}\text { Dry wt of cells } \\ \text { extracted } \\ \text { (mg per ml assay } \\ \text { suspension) }\end{array} & \begin{array}{c}\text { Percentage of } \\ \text { heterocysts } \\ \text { with a } \\ \text { contiguous } \\ \text { akinete }\end{array} \\ \geqslant 38.6 & \begin{array}{c}\text { Cells lysed } \\ 19.3\end{array} \\ 35.0 \\ 3.86 & 44.0 \\ 1.93 & 33.0 \\ 0.386 & 29.0 \\ 0.193 & 16.5 \\ 0.000 & 7.0\end{array}$

Table 2. Effect of hydrogen on the formation of akinetes

Values shown are the percentage of heterocysts with contiguous akinetes.

\begin{tabular}{ccc}
$\begin{array}{c}\text { Hydrogen } \\
(\%, \mathrm{v} / \mathrm{v})\end{array}$ & \multicolumn{2}{c}{ Remaining gas phase } \\
0 & $13 \cdot 5$ & $\mathrm{CO}_{2} / \mathrm{O}_{2} / \mathrm{Ar}^{*}$ \\
$5 \cdot 0$ & $26 \cdot 5$ & $13 \cdot 0$ \\
$10 \cdot 0$ & $26 \cdot 0$ & $16 \cdot 5$ \\
$12 \cdot 5$ & $34 \cdot 0$ & $18 \cdot 0$ \\
$15 \cdot 0$ & $25 \cdot 5$ & $27 \cdot 5$ \\
$20 \cdot 0$ & $25 \cdot 5$ & $28 \cdot 0$ \\
$* 0.1 \% \mathrm{CO}_{2} / 19.9 \%$ & $\mathrm{O}_{2} / 80 \% \mathrm{Ar}$.
\end{tabular}

Table 3. Effects of amino acids on the formation of akinetes

Values shown are the percentage of heterocysts with contiguous akinetes.

Amino acid

\begin{tabular}{|c|c|c|c|c|c|c|}
\hline \multicolumn{7}{|c|}{ Amino acid concn (mM) } \\
\hline 16 & 10 & 5 & 1 & 0.5 & $0 \cdot 1$ & 0 \\
\hline $8 \cdot 0$ & $10 \cdot 0$ & $7 \cdot 5$ & $6 \cdot 0$ & & & \\
\hline $10 \cdot 0$ & $10 \cdot 0$ & $10 \cdot 0$ & 1.5 & & & \\
\hline $31 \cdot 5$ & $10 \cdot 0$ & $9 \cdot 0$ & 6.0 & & & \\
\hline $20 \cdot 5$ & $8 \cdot 0$ & $6 \cdot 0$ & $5 \cdot 0$ & & & \\
\hline $47 \cdot 0$ & $25 \cdot 5$ & $26 \cdot 5$ & $22 \cdot 5$ & & & \\
\hline - & - & 6.0 & 18.5 & & & \\
\hline $1 \cdot 5^{*}$ & $3 \cdot 0 *$ & $0 \cdot 0$ & 0.0 & & & \\
\hline 一 & - & - & $4 \cdot 0^{*}$ & $3.5^{*}$ & 0.0 & \\
\hline - & - & 一 & - & - & $0 \cdot 0$ & \\
\hline - & - & - & $60 \cdot 5$ & $42 \cdot 0$ & $36 \cdot 0$ & \\
\hline $68 \cdot 5$ & $38 \cdot 0$ & $20 \cdot 5$ & $19 \cdot 0$ & & & \\
\hline $0 \cdot 0^{*}$ & $0 \cdot 0$ & 0.0 & $3 \cdot 0$ & & & \\
\hline - & - & $12 \cdot 5$ & $13 \cdot 5$ & & & \\
\hline - & 一 & 0.0 & $4 \cdot 5$ & & & \\
\hline 一 & - & $14 \cdot 0$ & $8 \cdot 5$ & & & \\
\hline 一 & - & $8 \cdot 0$ & $5 \cdot 0$ & & & \\
\hline - & - & $0 \cdot 0$ & 0.0 & & & \\
\hline $2 \cdot 5$ & $0.0^{*}$ & $0 \cdot 0$ & $0 \cdot 0$ & & & \\
\hline 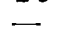 & - & $35 \cdot 0$ & $17 \cdot 0$ & & & \\
\hline
\end{tabular}

Control

Glu
Gln
Pro
Arg
Asp
Asn
Lys
Thr
Tyr
Trp
Phe
His
Ser
Gly
Cys
Ala
Val
Leu
Ile

-, Cells lysed. Cells also lysed in the presence of $0.1 \mathrm{~mm}$, or higher concentrations, of methionine. Methionine at $0.05 \mathrm{~mm}$ and below neither inhibited growth nor influenced sporulation.

* Inhibitory to growth. 
Table 4. Effects of acetylene and ethylene, in air, on the formation of akinetes

The mixture of gases was replaced every $12 \mathrm{~h}$. Values shown are the percentage of heterocysts with contiguous akinetes and, in parentheses, the growth of the culture during $4 \mathrm{~d}$, expressed as $\mu \mathrm{g}$ chlorophyll $a \mathrm{ml}^{-1}$ at the end of the $4 \mathrm{~d}$.

\begin{tabular}{lcccccccc} 
& \multicolumn{8}{c}{ Percentage $(\mathrm{v} / \mathrm{v})$ of ethylene or acetylene in air } \\
Ethylene & -0 & 0.001 & 0.01 & 0.1 & 0.5 & 1 & 5 & 10 \\
& 7.0 & 6.5 & $2 \cdot 0$ & $1 \cdot 0$ & 0 & 0 & & \\
Acetylene & $(0.51)$ & $(0.50)$ & $(0.46)$ & $(0 \cdot 50)$ & $(0 \cdot 46)$ & $(0.46)$ & & \\
& & & & & $6 \cdot 0$ & 0 & 0 & 0 \\
& & & & & $(0.48)$ & $(0.46)$ & $(0.48)$ & $(0.51)$
\end{tabular}

Table 5. Biological activity, in SSM and AA/8*, of the vacuum-distillate of the sporulationstimulatory material purified by the entire procedure of Hirosawa \& Wolk (1979)

Activity is expressed as the percentage of heterocysts with contiguous akinetes.

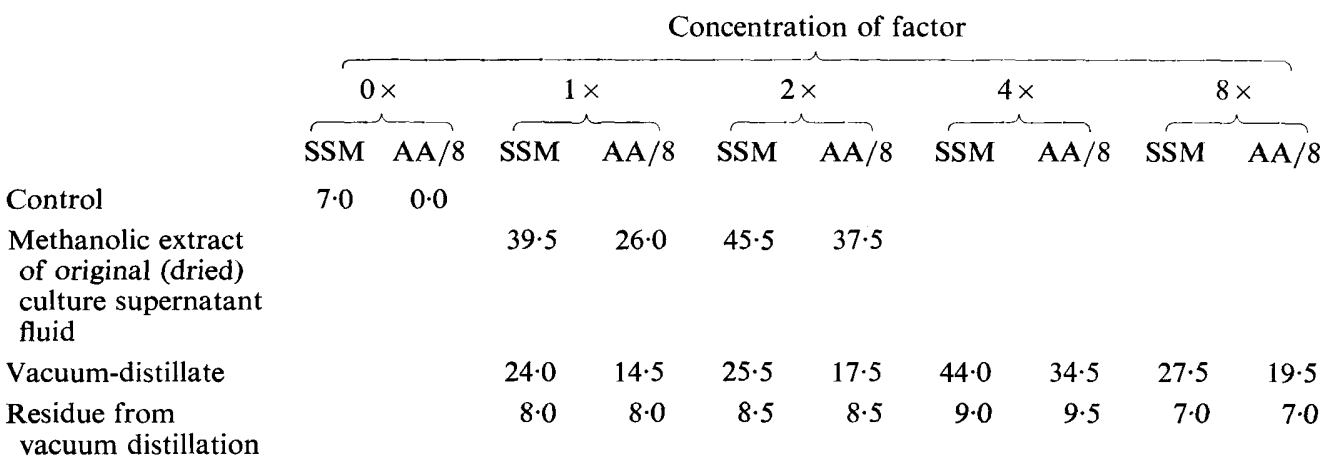

* Akinetes which formed in AA/8 were able to complete morphological maturation in that medium despite the fact that it contains all of the elements required for vegetative growth.

isolated heterocysts, whereas no activity was detected in a fraction derived from vegetative cells.

Effects of various substances of low molecular weight on the formation of akinetes. We examined the effects of the 20 amino acids usually found in proteins on the formation of akinetes (Table 3 ). L-Tryptophan ( $1 \mathrm{~mm}$ ) showed particularly high stimulatory activity. Aspartic acid and phenylalanine (at $16 \mathrm{~mm}$ ) also had high activity. Lower, but significant, stimulatory activity was shown by proline $(16 \mathrm{~mm})$ and isoleucine $(5 \mathrm{~mm})$. In the presence of SSM, containing or lacking sporulation-stimulatory active material, the cyclic nucleotides dibutyryl cyclic AMP (2.5 and $5.0 \mathrm{~mm})$, dibutyryl cyclic GMP $(0.5$ and $2.5 \mathrm{mM})$ and cyclic AMP $(0.5$ and $2.5 \mathrm{~mm})$ had little or no effect on the formation of akinetes, and neither did $\mathrm{NH}_{4} \mathrm{Cl}$ (up to $5.0 \mathrm{~mm}$ ) except at growth-inhibitory concentrations (i.e. at $1.0 \mathrm{~mm}$ and above in sporulation-stimulatory supernatant fluid). The formation of akinetes was completely inhibited by $1.0 \%$ acetylene or $0.5 \%$ ethylene (Table 4 ).

Calcium glucuronate (from Mann Research Laboratories), reported by Wolk (1965) to stimulate the formation of chains of akinetes in A. cylindrica, did not elicit the differentiation of chains of akinetes in C. licheniforme. However, after $4 \mathrm{~d}$ culture in SSM supplemented with $25 \mathrm{~mm}$-calcium glucuronate, an akinete was present adjacent to every heterocyst. Growth was not affected. In control cultures in SSM, about $5 \%$ of the heterocysts had contiguous akinetes.

In the presence of the sporulation-stimulatory substance purified from $C$. licheniforme 


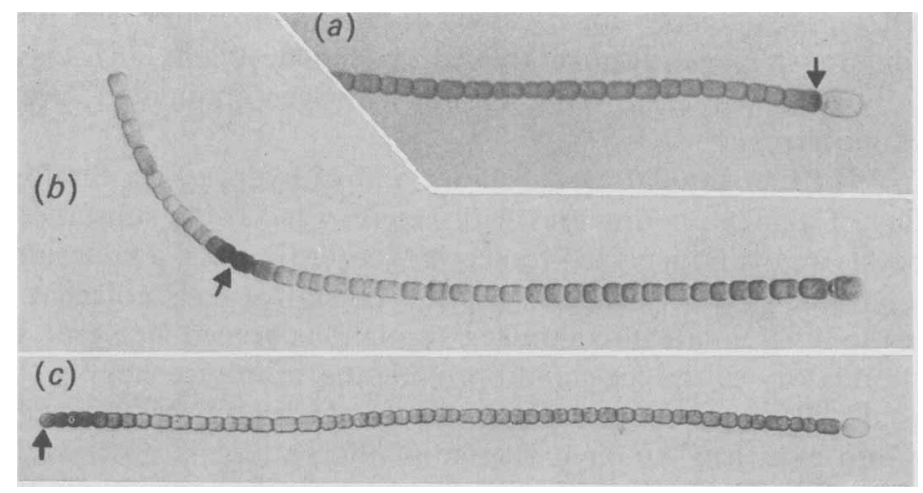

Fig. 3. Reduction of nitro blue tetrazolium chloride by (a) intact, (b) bent and (c) cut filaments. The arrows indicate the site of reduced tetrazolium in $(a)$ and $(b)$ and the cell to the left of which the cut was made in $(c)$.

(Hirosawa \& Wolk, 1979), the formation of akinetes was stimulated in AA/8 as well as in SSM (Table 5).

Cytochemistry with a redox dye. Fay \& Kulasooriya (1972) reported that when filaments of Anabaena cylindrica were treated under air with nitro blue tetrazolium chloride (NBT), a gradient of the amount of formazan produced by reduction of the NBT was observed, with the most formazan present in vegetative cells next to heterocysts and with the amount of formazan present per cell gradually diminishing with increasing distance from heterocysts. As shown in Fig. 3, such a gradient can form in $C$. licheniforme from any point of the filament which is gently bent mechanically, without any appearance of having been harmed, or is cut by a fine glass needle. Therefore, the gradient originally shown may be the consequence of localized penetration of NBT at the connection between heterocysts and vegetative cells rather than of a gradient of reducing activity.

\section{DISCUSSION}

The observation that the sporulation-stimulatory activity in culture supernatant fluids increases during the exponential phase of growth suggests that a stimulatory substance is released by healthy cells. The interpretation that the active substance is not a product of decomposition is supported by the observation that significant stimulatory activity may be extracted from the cells themselves. Because the purified substance (Hirosawa \& Wolk, 1979) stimulates sporulation in medium AA/8, which contains phosphate, this substance is not merely a promoter of a developmental process which occurs in response to a deficiency of phosphate, but itself initiates the differentiation of akinetes. The substance, which is maximally active at $0.3 \mu \mathrm{M}$ (Hirosawa \& Wolk, 1979), is the first example of an organic compound secreted by a cyanobacterium which specifically affects the differentiation process in the cyanobacterium.

Hydrogen gas is also active in stimulating sporulation adjacent to heterocysts. In Anabaena strain 7120, the uptake hydrogenase is restricted to heterocysts (Peterson \& Wolk, $1978 a$ ). The uptake hydrogenase of $C$. licheniforme also appears to be restricted to heterocysts because, in our experiments, isolated heterocysts accounted for $84 \%$ of the uptake hydrogenase present in filaments of the organism, as assayed in vitro. Because the effect of hydrogen on sporulation is therefore apparently mediated by heterocysts, these results provide additional support for the idea that heterocysts play a role in the sporulation of contiguous vegetative cells. Although hydrogen can serve as electron donor to nitrogenase (Wolk \& Wojciuch, 1971; Tel-Or et al., 1977; Peterson \& Wolk, 1978b) and at high concentration even inhibits nitrogenase (Wolk et al., 1974), the stimulation of sporulation by 
hydrogen cannot be mediated by an effect on the fixation of nitrogen for two reasons: first, hydrogen did not significantly affect the reduction of acetylene, an alternative substrate of nitrogenase, by $C$. licheniforme; and second, hydrogen stimulated sporulation under a gas phase lacking nitrogen.

What is the role of the stimulatory substance and of hydrogen in the formation of the pattern consisting of akinetes contiguous with heterocysts? If the substance is synthesized solely in heterocysts and is transported to nearby vegetative cells, a concentration gradient of this compound could be formed, so that the vegetative cells adjacent to heterocysts would be the first to differentiate into akinetes. It might be argued, however, that exogenous supply of the stimulatory substance should provide the substance equally to all vegetative cells and so should change the pattern into one in which all vegetative cells differentiate simultaneously into akinetes. No such change of the pattern is observed. It is possible, however, that the substance can enter the filaments only at the connections between heterocysts and vegetative cells. That such a localized penetration is possible is suggested by the results of experiments with nitro blue tetrazolium chloride (Fig. 3). In those experiments, the dye was reduced in cells contiguous with heterocysts and in any other cell which was bent or was close to a cut cell. Thus, vegetative cells contiguous with heterocysts may contain loci, such as, perhaps, the junctions to heterocysts, which are more permeable than are other sites along the filaments. If any stimulatory substance (including calcium glucuronate) can enter the filaments of $C$. licheniforme only through the vegetative cells contiguous with heterocysts, or must be metabolized by heterocysts in order to exert a developmental effect, the site of formation of a concentration gradient would be unchanged, as would be the pattern of formation of akinetes.

If heterocysts are not the sole site of the synthesis of the stimulatory substance or if the exogenously supplied stimulatory substance permeates into all vegetative cells, what can control the pattern? The stimulation of the formation of akinetes by hydrogen suggests that the pattern may be controlled by some substance (other than nitrogen: see above) which is reduced by the uptake hydrogenase in heterocysts, and then moves into neighbouring vegetative cells. As alluded to in the Introduction, reducing conditions may well characterize the interior of heterocysts, which might therefore provide an excess of some reductant to vegetative cells. An effect of hydrogen might be mediated, less directly, by a stimulation of oxidative phosphorylation in heterocysts (Peterson \& Burris, 1978). Yet another possibility, which cannot be excluded, is that hydrogen increases the inactivation, by heterocysts, of a sporulation-inhibitory substance.

Both acetylene and the product of its reduction by nitrogenase, ethylene, inhibit the formation of akinetes. From the rate of reduction of acetylene [12.3 $\mu \mathrm{mol}$ (mg chlorophyll $a)^{-1} \mathrm{~h}^{-1}$ ] and the concentration of chlorophyll ( $9 \cdot 6 \mu \mathrm{g}$ per flask) at the end of the period of assaying the effect of gases on the formation of akinetes, the amount of ethylene produced during the final $12 \mathrm{~h}$ of that period may be calculated to be $0.012 \%$ of the $280 \mathrm{ml}$ effective volume of the flask. The inhibition of sporulation by acetylene is therefore too great to be attributed solely to the ethylene produced from the acetylene, but may be ascribed to a combination of that ethylene and the acetylene itself. We know of no earlier reports of effects of a low concentration of ethylene on a prokaryote.

The observation that low concentrations of tryptophan stimulate sporulation gains interest from the fact that among the amino acid analogues tested by Mitchison \& Wilcox (1973), only 7-azatryptophan altered the pattern of spacing of heterocysts. Phenylalanine, another aromatic amino acid, also strongly stimulated sporulation, although at a 16-fold greater concentration. It is possible that these aromatic amino acids are normally involved in the control of the differentiation of akinetes. 
We thank Dr Richard B. Peterson for assistance with studies on the in-vitro assay and localization of hydrogenase, and Professor K. Raschke for assistance with photomicrography. This work was supported by the U.S. Department of Energy under Contract EY-76-C-02-1338.

\section{REFERENCES}

Allen, M. B. \& Arnon, D. I. (1955). Studies on nitrogen-fixing blue-green algae. I. Growth and nitrogen fixation by Anabaena cylindrica Lemm. Plant Physiology 30, 366-372.

Apte, S. K., Rowell, P. \& Stewart, W.D.P. (1978). Electron donation to ferredoxin in heterocysts of the $\mathrm{N}_{2}$-fixing alga Anabaena cylindrica. Proceedings of the Royal Society B200, 1-25.

Canabaeus, L. (1929). Über die Heterocysten und Gasvakuolen der Blaualgen und ihre Beziehung zueinander. Pflanzenforschung 13, 1-48.

Clark, R. L. \& Jensen, T. E. (1969). Ultrastructure of akinete development in a blue-green alga, Cylindrospermum sp. Cytologia 34, 439-448.

DraWert, H. \& Tischer, I. (1956). Über RedoxVorgänge bei Cyanophyceen unter besonderer Berücksichtigung der Heterocysten. Naturwissenschaften 43, 132.

Drews, G. (1955). Zur Frage der TTC-Reduktion durch Cyanophyceen. Naturwissenschaften 42, 646.

Fay, P. \& Kulasooriya, S. A. (1972). Tetrazolium reduction and nitrogenase activity in heterocystous blue-green algae. Archiv für Mikrobiologie 87, 341-352.

Fisher, R. W. \& Wolk, C. P. (1976). Substance stimulating the differentiation of spores of the blue-green alga Cylindrospermum licheniforme. Nature, London 259, 394-395.

FoGG, G. E. (1952). The production of extracellular nitrogenous substances by a blue-green alga. Proceedings of the Royal Society B139, 372-397.

Fujita, Y., Ohama, H. \& Hattori, A. (1964). Hydrogenase activity of cell-free preparation obtained from the blue-green alga, Anabaena cylindrica. Plant and Cell Physiology 5, 305-314.

Gentile, J. H. \& Maloney, T. E. (1969). Toxicity and environmental requirements of a strain of Aphanizomenon flos-aquae (L.) Ralfs. Canadian Journal of Microbiology 15, 165-173.

Glade, R. (1914). Zur Kenntnis der Gattung Cylindrospermum. Beiträge zur Biologie der Pflanzen 12, 295-346.

HARDER, R. (1917). Ernährungsphysiologische Untersuchungen an Cyanophyceen, hauptsächlich dem endophytischen Nostoc punctiforme. Zeitschrift für Botanik 9, 145-242.

Hartman, R. T. (1960). Algae and metabolites of natural waters. In The Ecology of Algae, special publication no. 2, Pymatuning Laboratory of Field Biology, University of Pittsburgh, pp. 38-55. Edited by C. A. Tyron, Jr \& R. T. Hartman.

HASElKorn, R. (1978). Heterocysts. Annual Review of Plant Physiology 29, 319-344.

Hirosawa, T. \& Wolk, C. P. (1979). Isolation and characterization of a substance which stimulates the formation of akinetes in the cyanobacterium Cylindrospermum licheniforme Kütz. Journal of General Microbiology 114, 433-441.
JACKIM, E. \& Gentile, J. (1968). Toxins of a bluegreen alga: similarity to saxitoxin. Science 162, 915-916.

JAKOB, H. (1961). Compatibilités, antagonismes et antibioses entre quelques algues du sol. Revue générale de botanique 68, 5-72.

LEX, M. \& CARR, N. G. (1974). The metabolism of glucose by heterocysts and vegetative cells of Anabaena cylindrica. Archives of Microbiology 101, $161-167$.

Lockau, W., Peterson, R. B., Wolk, C. P. \& BurRIS, R. H. (1978). Modes of reduction of nitrogenase in heterocysts isolated from Anabaena species. Biochimica et biophysica acta 502, 298-308.

MACKINNEY, G. (1941). Absorption of light by chlorophyll solutions. Journal of Biological Chemistry 140, 315-322.

Mitchison, G. J. \& Wilcox, M. (1973). Alteration in heterocyst pattern of Anabaena produced by 7-azatryptophan. Nature New Biology 246, 229233.

Peterson, R. B. \& Burris, R. H. (1978). $\mathrm{H}_{2}$ metabolism in isolated heterocysts of Anabaena 7120. Archives of Microbiology 116, 125-132.

Peterson, R. B. \& Wolk, C. P. (1978a). Localization of an uptake hydrogenase in Anabaena. Plant Physiology 61, 688-691.

Peterson, R. B. \& Wolk, C. P. (1978b). Localization and activity of nitrogenase in heterocysts isolated from Anabaena variabilis by a new procedure. Abstracts of the 3rd International Symposium on Nitrogen Fixation, Madison, Wisconsin.

Prescott, G. W. (1960). Biological disturbances resulting from algal populations in standing waters. In The Ecology of Algae, special publication no. 2, Pymatuning Laboratory of Field Biology, University of Pittsburgh, pp. 22-37. Edited by C. A. Tyron, Jr \& R. T. Hartman.

SimoN, R. D. (1971). Cyanophycin granules from the blue-green alga Anabaena cylindrica: a reserve material consisting of copolymers of aspartic acid and arginine. Proceedings of the National Academy of Sciences of the United States of America 68, 265-267.

SimoN, R. D. (1977). Sporulation in the filamentous cyanobacterium Anabaena cylindrica. The course of spore formation. Archives of Microbiology 111, 283-288.

Simpson, F. B. \& Neilands, J. B. (1976). Siderochromes in Cyanophyceae: isolation and characterization of schizokinen from Anabaena sp. Journal of Phycology 12, 44-48.

STANIER, R. Y. \& CoHen-BazIRE, G. (1977). Phototrophic prokaryotes: the cyanobacteria. Annual Review of Microbiology 31, 225-274.

Stewart, W. D. P., Haystead, A. \& Pearson, H. W. (1969). Nitrogenase activity in heterocysts of blue-green algae. Nature, London 224, 226-228. TAlPasay, E. R.S. \& BaHAL, M. R. (1967). 
Cellular differentiation in Anabaena cylindrica. Zeitschrift für Pflanzenphysiologie 56, 100-101.

Tel-Or, E., LuIJK, L. W. \& PaCKer, L. (1977). An inducible hydrogenase in cyanobacteria enhances $\mathrm{N}_{2}$ fixation. FEBS Letters 78, 49-52.

Thomas, J., Meeks, J. C., Wolk, C. P., Shaffer, P. W., Austin, S. M. \& Chien, W.-S. (1977). Formation of glutamine from $\left[{ }^{13} \mathrm{~N}\right]$ ammonia, $\left[{ }^{13} \mathrm{~N}\right]$ dinitrogen, and $\left[{ }^{14} \mathrm{C}\right]$ glutamate by heterocysts isolated from Anabaena cylindrica. Journal of Bacteriology 129, 1545-1555.

TYAGI, V. V.S. (1974). Some observations on the pattern of sporulation in a blue-green alga, Anabaena doliolum. Annals of Botany 38, 11071111.

WALSBY, A. E. (1974). The extracellular products of Anabaena cylindrica Lemm. I. Isolation of a macromolecular pigment-peptide complex and other components. British Phycological Journal 9, 371-381.

Whitton, B. A. (1965). Extracellular products of blue-green algae. Journal of General Microbiology 40, 1-11.

Whitron, B. A. (1967). Studies on the toxicity of polymyxin B to blue-green algae. Canadian Journal of Microbiology 13, 987-993.

Winkenbach, F. \& Wolk, C. P. (1973). Activities of enzymes of the oxidative and the reductive pentose phosphate pathways in heterocysts of a blue-green alga. Plant Physiology 52, 480-483. Wolk, C.P. (1965). Control of sporulation in a blue-green alga. Developmental Biology 12, 15-35.

Wolk, C. P. (1966). Evidence of a role of heterocysts in the sporulation of a blue-green alga. American Journal of Botany 53, 260-262.

WoLK, C. P. (1968). Movement of carbon from vegetative cells to heterocysts in Anabaena cylindrica. Journal of Bacteriology 96, 2138-2143.

Wolk, C. P. \& WoJciuch, E. (1971). Photoreduction of acetylene by heterocysts. Planta 97, 126-134.

Wolk, C. P., Austin, S. M., Bortins, J. \& Galonsky, A. (1974). Autoradiographic localization of ${ }^{13} \mathrm{~N}$ after fixation of ${ }^{13} \mathrm{~N}$-labeled nitrogen gas by a heterocyst-forming blue-green alga. Journal of Cell Biology 61, 440-453.

Zastrow, E. M. von (1953). Uber die Organisation der Cyanophyceenzelle. Archiv für Mikrobiologie 19, 174-205. 